\title{
Outcome after Resection of One Hundred Gastrointestinal Stromal Tumors
}

\author{
K. Krajinovic ${ }^{a} \quad$ C.T. Germer ${ }^{a} \quad$ A. Agaimy ${ }^{b} \quad$ P.H. Wünsch ${ }^{c} \quad$ C. Isbert ${ }^{a}$ \\ a Department of General, Vascular and Pediatric Surgery, Wuerzburg University Hospital, Wuerzburg, \\ ${ }^{b}$ Department of Pathology, Erlangen University Hospital, Erlangen, and 'Department of Pathology, \\ Klinikum Nürnberg Nord, Nuremberg, Germany
}

\section{Key Words}

Gastrointestinal stromal tumors $\cdot$ Complete tumor

resection $\cdot$ Prognostic factors $\cdot$ Mitotic index

\begin{abstract}
Aims: To evaluate the outcome after surgical resection in patients with gastrointestinal stromal tumors and to determine the factors influencing local tumor recurrence or distant metastatic disease after locally complete tumor resection (R0). Methods: Outcomes of 100 patients with primary gastrointestinal stromal tumors (GIST) surgically managed between 1997 and 2006 at a single institution were reviewed. Univariate and bivariate analyses were used to determine factors affecting recurrence-free and tumor-free survival. Results: All patients $(n=100)$ had c-kit-positive GIST. There were $17 \%(n=17)$ very low risk, $41 \%(n=41)$ low risk, $19 \%$ $(n=19)$ intermediate risk and $23 \%(n=23)$ high risk GIST originating from the stomach, small bowel, colon and rectum. The median patient age was 68 years (range 39-92). Seventy-three percent of the patients had symptomatic local disease. Most $(94 \% ; n=94)$ of them underwent R0 resections of their primary tumor. R0 resection was significantly associated with a lower tumor-related mortality rate $(p=$ $0.0001)$. The patients with recurrence/metastases had significantly larger tumors $(p=0.0017)$ and a mitotic index higher
\end{abstract}

than $5 / 50$ HPF $(p=0.0001)$. Seven of 20 patients from the high-risk group and 2 of 7 patients with metastatic disease developed local recurrence or further metastatatic tumor spread following R0 resection. Conclusion: Surgical removal continues to be the mainstay of GIST treatment. RO resection, tumor size and mitotic index are significant prognostic factors. Overall, more than $30 \%$ of the patients with high-risk GIST develop local recurrences and distant metastases despite Ro resection. Additional molecular pathological markers are needed to yield a more accurate tumor profile and to thus achieve a better predictability of the biological behavior of GIST.

Copyright $\odot 2010$ S. Karger AG, Basel

\section{Introduction}

Following the discovery of activating c-kit mutations and demonstration of c-kit (CD 117) immunoexpression on the surface of tumor cells in the majority of mesenchymal GI neoplasms formerly classified as smooth muscle or neurogenic neoplasms, gastrointestinal stromal tumors (GISTs) were redefined as an independent tumor entity. The incidence of GISTs is estimated to be 14.5 cases per million people per year [1]. The surgical R0 resection continues to be the treatment of choice for resectable

\section{KARGER}

Fax +4161306 1234 E-Mail karger@karger.ch www.karger.com
Katica Krajinovic

Department of General, Vascular and Pediatric Surgery

Würzburg University Hospital, Oberdürrbacher Strasse 6

DE-97080 Würzburg (Germany)

Tel. +49 93120131 171, E-Mail krajinovic_k@klinik.uni-wuerzburg.de 
tumors. Diverse prognostic factors that would predict the development of recurrence and/or metastases after R0 resection of GIST have been evaluated by several research groups worldwide, in particular for the category of highrisk tumors. The question whether adjuvant treatment with imatinib is indicated in patients with R0-resected high-risk GISTs has not yet been conclusively settled. The objectives of this large single-center trial were to evaluate the outcome after surgical resection and determine the prognostic factors for tumor relapse and tumor-related death.

\section{Materials and Methods}

\section{Patients}

Follow-up data of patients who underwent surgery due to a GIST between January 1, 1997, and December 31, 2006, at the Department of Surgery of the Klinikum Nürnberg Nord were obtained and analyzed based on a questionnaire consisting of 36 questions regarding the patient's personal data, symptoms, macroscopic and histological features of the tumors, location and time until tumor recurrence or metastases, drug therapy, type and length of follow-up after primary resection and cause of death. These data were collected methodically in terms of personal interviews with the patients or their families and the attending primary care physicians. The risk group assessment was done by evaluating maximum tumor size and mitotic index according to the Fletcher risk assessment system [2] (table 1).

In all cases in which a safe $\mathrm{R} 0$ resection could be carried out while still preserving the organs, a limited organ-preserving resection was performed. Wedge resections of the stomach and intestinal segment resections were also counted as part of this group.

Patients who exhibited a locally progressive tumor with infiltration of neighboring organs received an en bloc multivisceral resection to ensure a safe $\mathrm{R} 0$ status. A systematic lymph node dissection was not performed.

We distinguished the type of tumor relapse into recurrence and metastases. Recurrence is defined as local recurrence in the already operated organ, and metastases are defined as tumor formation in other locations. Tumor relapse includes recurrence and metastases.

\section{Statistical Methods}

The frequency distribution of the two independent groups was calculated using Fisher's exact test to determine if significant differences exist. Comparison of the distribution of a metric variable of two independent groups was made using the Mann-Whitney U test. All tests were calculated two-sided with a significance level set at $\mathrm{p}=0.05$.

To test the simultaneous influence of several variables on a binary target variable, logistic regressions were carried out.

The Kaplan-Meier method was used to calculate survival time and/or recurrence-free and metastases-free time. This also includes times of censored observations. Censored values are the times of patients who are living and/or who have not developed
Table 1. Risk stratification of GISTs according to the Fletcher risk assessment system [2]

\begin{tabular}{lcl}
\hline Malignancy risk & $\begin{array}{l}\text { Tumor size } \\
\mathrm{cm}\end{array}$ & $\begin{array}{l}\text { Mitotic index/ } \\
50 \mathrm{HPF}\end{array}$ \\
\hline Very low risk & $<2$ & $<5$ \\
Low risk & $2-5$ & $<5$ \\
Intermediate risk & $<5$ & $6-10$ \\
& $5-10$ & $<5$ \\
High risk & $5-10$ & $>5$ \\
& unrelated & $>10$ \\
& $>10$ & unrelated \\
\end{tabular}

any recurrence or metastases (then survival time corresponds to the observation time). All values are presented as mean with range.

The period from operation to detection of the first tumor recurrence or metastases was defined as the recurrence-free interval. Patients who were free of recurrence or metastasis at the last follow-up examination and patients who died and whose death was not due to GIST were captured in the analysis by the parameter tumor-free survival time.

Patients without indications of a localized recurrent tumor or metastases were included in the analysis of recurrence-free survival; here patients with persisting disease were excluded.

Patients in the metastasized stage were considered separately. All statistical analyses were conducted using SAS 9.1 for Windows.

\section{Results}

\section{Patient and Tumor Characteristics}

The analysis included 100 patients (54 female and 46 male) with an age range between 39 and 92 years (median age 67.8 years).

The average follow-up observation time was 4.9 years (range 3.6 months to 10.1 years). Seventy-three patients (73\%) had tumor-related symptoms. Twenty patients (21.5\%) had other synchronous malignancies. These patients with second malignancies have been included in a previous review [3].

The most common tumor site was the stomach $(\mathrm{n}=$ 67), followed by the jejunum/ileum $(n=20)$, duodenum $(\mathrm{n}=10)$, colon $(\mathrm{n}=2)$ and $(\mathrm{n}=1)$ rectum.

The average (statistical mean) tumor size was $1.2 \mathrm{~cm}$ (range $0.6-2.0 \mathrm{~cm}$ ) for tumors in the very-low-risk group versus a mean size of $9.1 \mathrm{~cm}$ (range $3.0-23.0 \mathrm{~cm}$ ) in the high-risk group. Based on the risk stratification according to the NIH consensus criteria [2] (table 1), tumors 
Table 2. Clinical data and tumor characteristics of 100 GIST patients

\begin{tabular}{|c|c|c|c|c|c|c|c|}
\hline Tumor size & $\begin{array}{l}\text { Mitotic index } \\
\text { pro } 50 \mathrm{HPF}\end{array}$ & Risk group & $\mathrm{n}$ & R0 & $\mathrm{R} 1$ & $\mathrm{R} 2$ & $\begin{array}{l}\text { Recurrence/metastases } \\
\text { after R0 resection }\end{array}$ \\
\hline$<2 \mathrm{~cm}$ & $<5$ & very low & 16 & 16 & 0 & 0 & 0 of 16 \\
\hline $2-5 \mathrm{~cm}$ & $<5$ & low & 38 & 38 & 0 & 0 & 0 of 38 \\
\hline$<5 \mathrm{~cm}$ & $6-10$ & intermediate & 18 & 18 & 0 & 0 & 2 of 18 \\
\hline $5-10 \mathrm{~cm}$ & $<5$ & & & & & & \\
\hline $5-10 \mathrm{~cm}$ & $>5$ & high risk & 21 & 20 & 1 & 0 & 7 of 20 \\
\hline $\begin{array}{l}\text { Unrelated } \\
>10 \mathrm{~cm}\end{array}$ & $\begin{array}{l}>10 \\
\text { unrelated }\end{array}$ & & & & & & \\
\hline Metastasized & & & 7 & 2 & 0 & 5 & 2 of 2 \\
\hline
\end{tabular}

Table 3. Descriptive characteristics of the tumor size $(\mathrm{cm})$ of R0-resected patients ${ }^{1}$

\begin{tabular}{lrcccccccc}
\hline & $\mathrm{n}$ & Mean & STDDEV & Min. & $\begin{array}{l}\text { 25\% } \\
\text { percentile }\end{array}$ & Median & $\begin{array}{l}75 \% \\
\text { percentile }\end{array}$ \\
\hline Without recurrence/metastases & 84 & 4.62 & 4.18 & 0.60 & 2.00 & 3.45 & 6.00 & 23.0 & 0.017 \\
Recurrence or metastases & 8 & 7.10 & 4.25 & 4.00 & 4.40 & 6.00 & 7.50 & 17.0 \\
\hline
\end{tabular}

* p value of Mann-Whitney U test on differences of medians of the two groups.

${ }^{1}$ Without the patients with metastasizing GIST.

were classified as very low risk $(\mathrm{n}=16)$, low risk $(\mathrm{n}=38)$, intermediate risk $(\mathrm{n}=18)$ and high risk $(\mathrm{n}=2)$ (table 2$)$. All patients in the very-low-risk and low-risk groups had a mitotic index of $<5 / 50 \mathrm{HPF}$ (table 1 ). In contrast, a mitotic index $>5 / 50 \mathrm{HPF}$ was noted in $4(22.2 \%)$ of the patients of the intermediate-risk group and in 19 (90.5\%) of the patients in the high-risk group.

\section{Survival and Prognostic Factors}

The tumor status at the time of therapy is represented with reference to the risk profile in table 2 . The average follow-up was 4.9 years (range 3.6 months to 10.1 years). No recurrence was observed in any of the cases from the very-low-risk, low-risk and intermediate-risk groups following R0 resection. In the group with high-risk tumors $(\mathrm{n}=21)$, there were 2 recurrences $(9.5 \%)$ after R0 resection.

The average tumor size in cases with recurrent/metastatic disease after R0 resection was $7.0 \mathrm{~cm}$ (range 4.0 $17.0 \mathrm{~cm}$ ) and thus significantly larger compared to a mean size of $4.6 \mathrm{~cm}$ (range $4.18-23 \mathrm{~cm}$ ) for those who remained disease-free at last follow-up ( $\mathrm{p}=0.017$; table 3$)$. The average time to recurrence or metastases following R0 resec- tion was 14 months in the intermediate-risk group and 23 months in the high-risk group.

Another significant difference could be found between the patient groups with and without recurrence/ metastases: the patients with recurrence/metastases had a mitotic index greater than $5(\mathrm{p}=0.0001$, table 4$)$.

Four of the 21 patients (19.1\%) in the high-risk group and 5 of the 7 patients (71.4\%) in the subgroup with metastasized tumors died due to the tumor.

Within the high-risk group, the patients who were alive and tumor-free at the time of follow-up $(n=9)$ were compared with the patients who were not tumor-free or who died due to the tumor $(\mathrm{n}=7)$. Concerning age $(\mathrm{p}=$ $0.490)$, gender $(p=0.615)$ and average size $(p=0.458)$ of the tumors, there were no significant differences between the groups.

We also could not find a statistically significant difference in the behavior of small bowel GIST compared to GIST of the stomach in our evaluation.

Furthermore, R1/R2-resected patients had a significantly higher ( $\mathrm{p}=0.0001$; table 5$)$ tumor-related mortality rate than $\mathrm{R} 0$-resected patients. 
Table 4. Relationship between recurrence/metastasis and mitotic index in the group of R0-resected patients ${ }^{1}$

\begin{tabular}{|c|c|c|c|c|c|}
\hline \multirow[t]{3}{*}{ Group } & \multicolumn{4}{|c|}{ Mitotic index } & \multirow[t]{3}{*}{ p value* } \\
\hline & \multicolumn{2}{|l|}{$\leq 5$} & \multicolumn{2}{|l|}{$>5$} & \\
\hline & index & $\%^{2}$ & index & $\%^{2}$ & \\
\hline Without recurrence/metastasis & 69 & 98.6 & 1 & 1.4 & 0.0001 \\
\hline Recurrence or metastases & 15 & 68.2 & 7 & 31.8 & \\
\hline
\end{tabular}

* $\mathrm{p}$ value of the Fisher exact test.

${ }^{1}$ Without the patients with metastasizing GIST.

2 The percentages refer to the percentage of patients with a mitotic index $\leq 5 />5$ within the groups (line total $=100 \%)$.

Table 5. Correlation between status of resection and tumor-related death

\begin{tabular}{|c|c|c|c|c|c|c|c|}
\hline \multirow[t]{2}{*}{ Resection status } & \multicolumn{2}{|c|}{ Survivor } & \multicolumn{2}{|c|}{ Death unrelated to tumor } & \multicolumn{2}{|c|}{ Death due to tumor } & \multirow[t]{2}{*}{$\mathrm{p}$} \\
\hline & $\mathrm{n}$ & $\%$ & $\mathrm{n}$ & $\%$ & $\mathrm{n}$ & $\%$ & \\
\hline R0 & 67 & 71.3 & 21 & 22.3 & 6 & 6.4 & 0.0001 \\
\hline $\mathrm{R} 1 / \mathrm{R} 2$ & 1 & 16.7 & & & 5 & 83.3 & \\
\hline
\end{tabular}

The percentages refer to the fraction of survivor/unrelated to tumor death and death due to tumor within the subgroups (line total $=100 \%$ ).

\section{Discussion}

The objective of this study was to evaluate the outcome of GIST patients based on resection extent, tumor size and mitotic index. This large single-center study comprised 100 consecutive patients who underwent surgery for a GIST in our clinic between 1997 and 2006. We included those patients in the total study cohort who were admitted to our clinic for a primary GIST resection. In 7 cases, the patients had already had a primary resection in other hospitals and were also receiving imatinib drug therapy before presenting in our clinic for resection of metastases or a recurrent tumor. We studied these patients separately and did not include them in the overall analysis.

Our results show that the GIST prognosis is decisively influenced by the radicality of surgical resection, tumor size and the mitotic index. The rate of achieved complete resections was $94 \%$ in our study, similar to those of 86 and 90\% in the studies of DeMatteo et al. [4] and Langer et al. [5], respectively. The $\mathrm{R} 0$ resection rates described in the reference literature varied between 50 and $90 \%[4,6,7]$.
This range of fluctuation of the $\mathrm{R} 0$ resection rate is due to the tumor characteristics of the studied patients. The rate of $94 \%$ in our study surely refers to the predominant fraction of patients committed to our institute with primary resectable tumors. In our patient groups, the R1/R2-resected patients had a significantly higher tumor-related mortality rate than the R0-resected patients (fig. 1).

These results agree with other studies showing better overall survival in the group of patients with a complete tumor removal compared to those who did not undergo a radical operation [8-10].

Beside the extent of surgical resection, the pathologic features tumor size and mitotic index are additional decisive predictors of outcome $[4,11]$. In the subgroup of patients $(\mathrm{n}=21)$ with tumors smaller than $2.5 \mathrm{~cm}$, there was no case of tumor-related death, and the probability of a tumor-associated death increased with the growing size of the tumor (fig. 2).

We were able to show significant differences as to tumor size and mitotic index between the patient groups with and without recurrences/metastases. The patients 


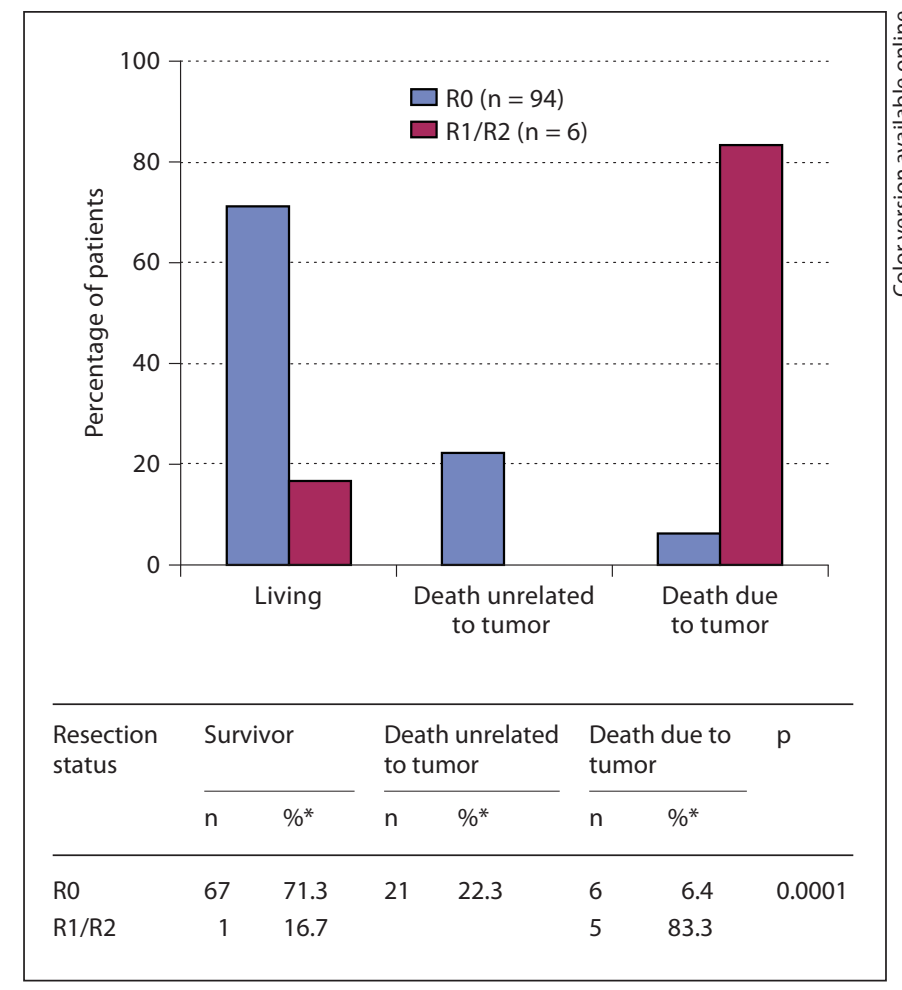

Fig. 1. Status of patients according to resection extent. ${ }^{*}$ Without patients who died not tumor-associated or with metastasizing GIST [the group of patients $(\mathrm{n}=21)$ with tumors $<2.5 \mathrm{~cm}$ is not included in the table, in this group there was no tumor-related death].

with recurrences/metastases presented a significantly higher incidence of a mitotic index greater than 5 and, on average, their tumors were larger.

These findings are consistent with the results of other studies, which identify tumor size and mitotic index as the two most reliable prognostic factors of outcome for GISTs [8, 12-14].

In our study groups, none of the patients with verylow, low- and intermediate-risk tumors developed tumor relapse after R0 resection, but metastases appeared in 2 (11\%) patients from the intermediate-risk group in the further course of the disease.

Thus, tumor size and low mitotic index cannot be equated in principle with a benign behavior of the tumor and correspondingly good prognosis [8, 14-17].

Despite complete resection, 7 (33.3\%) of 21 patients from the high-risk group relapsed or developed metastases in the further course of the disease, and no patient from the subgroup of patients with metastasized tumor was cured.

Outcome after Resection of

Gastrointestinal Stromal Tumors

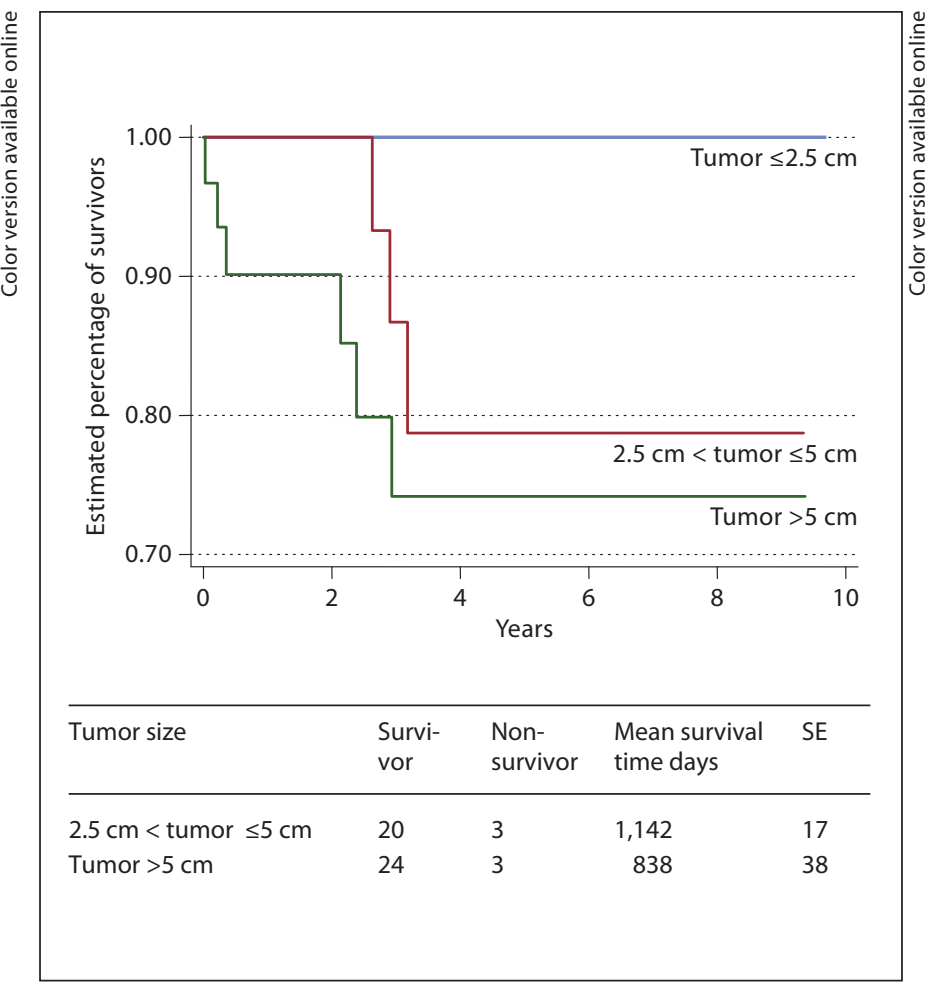

Fig. 2. Kaplan-Meier survival estimation related to tumor size.

In the studies of De Matteo et al. [4], Mudan et al. [16] and Samiian et al. [18], comparable recurrence rates of $40-70 \%$ in the high-risk group were described. These high incidences of recurrent and metastatic disease after complete surgical resection is the rationale for using imatinib in the adjuvant setting $[19,20]$.

The analysis of recurrence-free survival shows that it is difficult to unambiguously define the subgroup that should be administered an adjuvant therapy following complete resection of a high-risk GIST. To select those patients who may benefit most from the adjuvant therapy is still a challenge [21].

Worldwide, several studies concerning these issues are ongoing at the present time to assess imatinib therapy in a neoadjuvant and adjuvant intent. It will certainly take a number of years before definite results can be expected [22-25]. As Joensuu et al. [9] report, most recurrences and metastases appear in the first 5 years after the primary operation. This corresponds to the observations made in our patient cohort, where 2.8 years was the longest period

Dig Surg 2010;27:313-319 
it took for metastases to appear after the primary operation.

Most of the recurrences or metastases following R0 resection of a high-risk GIST appeared within 3 years following the primary operation. In other studies, disease recurrence or metastases were diagnosed within the first 2 years after initially complete surgical resection $[16,18]$. This discrepancy is possibly due to the nonstandardized and inconsistent postoperative follow-up of the patients.

As in the studies of other research groups $[8,11,14,26]$, the tumor recurrence and metastases occurred intraabdominally in all cases. Metastases outside of the abdomen, in particular bone and pulmonary metastases, are rare.

The average follow-up observation period in our study was 4.9 years. During this period we found no metastases or recurrences in patients in either of the two low-risk groups.

Accordingly, a standardized structured follow-up care in compliance with the recommendations of ESMO [27] should be carried out to possibly increase the detection rate of a resectable recurrent tumor mass or metastases at an early stage, thus facilitating a potentially curative surgical therapy.

Mudan et al. [16] report on single cases of late recurrences in the low-risk groups for up to 10 years after the primary operation.

The appearance of tumor relapse and metastases after R0 resection of GISTs [16] in these subgroups reveals a certain malignant tendency of all GISTs and, as a further consequence, demands the collection of data and structured long-term follow-up care of GIST patients regardless of their risk stratification.

Whether these individual observations justify lifelong follow-up examinations in all subgroups must still be determined within the framework of long-term studies of larger groups.

According to the latest data, the 3-year survival rate of patients with metastasized GIST under imatinib therapy was approximately $68 \%$ [28]. In the pre-imatinib era, the average length of survival for these patients was between 6 and 18 months [4].

Given that imatinib is a more oncostatic than cytotoxic drug [29] and that patients with progressive or metastasized tumor [30-32] can develop imatinib resistances [33], surgical resection should be considered upon development of a metabolically active, resectable recurrent tumor or metastases, regardless of whether symptoms are present or not.

Andtbacka et al. [34] were able to show improvement in overall survival after surgical $\mathrm{R} 0$ resection of recurrent tumors or metastases under imatinib therapy, and Aparicio et al. [35] were able to achieve an $\mathrm{R} 0$ resection in 40\% of the recurrences and metastases in their patient cohort, which was associated with a better outcome.

New mutations, despite otherwise good response to imatinib, can lead to isolated progressive metastases or tumor cells. Here the indication for surgical resection can be justified in individual cases $[34,36,37]$.

\section{Conclusion}

Complete surgical removal remains the only possibility of treating gastrointestinal tumors in a curative intent. Nevertheless, in the group of high-risk GIST, we encounter a large number of patients with tumor relapse or metastases despite complete surgical resection of the primary tumor. Beside the already existing prognostic markers, the molecular pathological tumor characterization could in the future contribute decisively to an optimized patient selection by generating exact prognostic variables for the tumor risk profile. With these predictors and correspondingly adapted adjuvant and neoadjuvant drugtherapy concepts, a clear increase in the curative rate and prolongation of survival are to be expected. As long as recurrences appear in all subgroups, structured followup examination of all GIST patients is called for regardless of risk category.

\section{References}

1 Nilsson B, Bümming P, Meis-Kindblom JM, Oden A, Dortok A, Gustavsson B, Sablinska K, Kindblom L-G: Gastrointestinal stroma tumors: the incidence, prevalence, clinical course, and prognostication in the preimatinib mesylate era - a population based study in western Sweden. Cancer 2005;103:821829.
2 Fletcher CD, Bermann JJ, Corless C, Gorstein F, Lasota J, Longley BJ, O'Leary TJ, Rubin BP, Sobin LH: Diagnosis of gastrointestinal stromal tumors: a consensus approach. Hum Pathol 2002;33:459-465.

3 Agaimy A, Wünsch PH, Sobin LH, Lasota J, Miettinen M: Occurrence of other malignancies in patients with gastrointestinal stromal tumors. Semin Diagn Pathol 2006; 23:120-129. 
4 De Matteo RP, Lewis JJ, Leung D, Mudan SS, Woodruff JM, Brennan MF: Two hundred gastrointestinal stromal tumors: recurrence patterns and prognostic factors for survival. Ann Surg 2000;231:51-58.

5 Langer C, Gunawan B, Schuler P, Huber W, Fuzesi L, Becker H: Prognostic factors influencing surgical management and outcome of gastrointestinal stromal tumours. Br J Surg 2003;90:332-339.

6 Wu P, Langerman B, Ryan C, Hart J, Swiger $\mathrm{S}$, Posner M: Surgical treatment of gastrointestinal stromal tumours in the imatinib (STI-571) era. Surgery 2003;134:656-665.

7 Bucher P, Villinger P, Egger J, Buhler L, Morel P: Management of gastrointestinal stromal tumours: from diagnosis to treatment. Swiss Med Wkly 2004;134:145-153.

8 Miettinen M, El-Rifai WE, Sobin LH, Lasota $\mathrm{J}$ : Evaluation of malignancy and prognosis of gastrointestinal stromal tumors: a review. Hum Pathol 2002;33:478-483.

9 Joensuu H, Fletcher C, Dimitrijevic S, Silbermann S, Roberts P, Demetri G: Management of malignant gastrointestinal stromal tumors. Lancet Oncol 2002;3:655-664.

10 Pidhorecky I, Cheney RT, Kraybill WG, et al: Gastrointestinal stromal tumors: current diagnosis, biologic behavior and management. Ann Surg Oncol 2000;7:705-712.

11 Pierie J-PEN, Choudry U, Muzikansky A, et al: The effect of surgery and grade on outcome of gastrointestinal stromal tumors. Arch Surg 2001;136:383-389.

12 Miettinen M, Makhlouf H, Sobin L, Lasota J: Gastrointestinal stromal tumors of the jejunum and ileum: a clinicopathologic, immunohistochemical, and molecular genetic study of 906 cases before imatinib with longterm follow up. Am J Surg Pathol 2006;30: 477-489.

13 Gupta M, Sheppard BC, Corless CL, MacDonell KR, Blanke CD, Billingsley KG: Outcome following surgical therapy for gastrointestinal stromal tumors. J Gastrointest Surg 2006;10:1099-1105.

14 Miettinen M, Majidi M, Lasota J: Pathology and diagnostic criteria of gastrointestinal stromal tumours (GISTs): a review. Eur J Cancer 2002;38(suppl 5):S39-S51.

15 Greenson JK: Gastrointestinal stromal tumors and other mesenchymal lesions of the gut. Mod Pathol 2003;16:366-375.
16 Mudan SS, Conlon KC, Woodruff JM, Lewis JJ, Brennan MF: Salvage surgery for patients with recurrent gastrointestinal sarcoma: prognostic factors to guide patient selection. Cancer 2000;88:66-74.

17 Tsukuda K, Hirat R, Miyake T, et al: The outcome of gastrointestinal stromal tumors (GISTs) after a surgical resection in our institute. Surg Today 2007;37:953-957.

18 Samiian L, Mitchell W, Velanovich V: Evaluation of gastrointestinal stromal tumors for recurrence rates and patterns of long-term follow-up. Am Surg 2004;70:187-192

19 Hsu KH, Yang TM, Shan YS, Lin PW: Tumor size is a major determinant of recurrence in patients with resectable gastrointestinal stromal tumor. Am J Surg 2007; 194:148-152.

20 Mucciarini C, Rossi G, Bertolini F, Valli R, et al: Incidence and clinicopathologic features of gastrointestinal stromal tumors. A population-based study. BMC Cancer 2007;7:230.

21 Chandrajit PR, Stanley WA: How I Do It Surgical Management of Gastrointestinal Stromal Tumors. J Gastrointest Surg 2008; 12:1592-1599.

22 DeMatteo RP: A phase III randomized double-blind study of adjuvant STI571(Gleevec) versus placebo in patients following the resection of primary gastrointestinal stromal tumor (GIST), 2001

23 DeMatteo RP: A phase II study of adjuvant STI571 (Gleevec) therapy in patients following completely resected high-risk primary gastrointestonal stromal tumor (GIST) 2001.

24 Casali PG: Phase III randomized study of adjuvant imatinib mesylate versus observation only in patients with completely resected localizes gastrointestinal stromal tumor at intermediate- or high-risk of relapse, 2004

25 Joensuu H: Phase III randomized study of short (12 months) versus long (36 months) duration of adjuvant treatment with the tyrosine kinase inhibitor imatinib mesylate of operable GIST with a high risk for recurrence, 2004.

26 Miettinen M, Salomo-Rikala M, Sobin LH, Lasota J: Gastrointestinal stromal tumors and leiomyosarcomas in the colon: a clinicopathologic, immunhistochemical, and molecular genetic study of 44 cases. Am J Surg Pathol 2000;24:1339-1352.

27 Blay JY, Bonvalot S, Casali P, et al: Consensus meeting for the management of gastrointestinal stromal tumors: report of the GIST Consensus Conference of 20-21 March 2004, under the auspices of ESMO. Ann Oncol 2005; 16:566-578.
28 Verweij J, Casali PG, Zalcberg J, LeCesne A, Reichardt P, Blay JY, Issels R, van Oosterom A, Hagendoorn PCW, van Glabbeke M, Bertulli R, Judson I: Progression-free survival in gastrointestinal stromal tumours with highdose imatinib: randomised trial. Lancet 2004;364:1127-1134.

29 Gold JS, DeMatteo RP: Combined surgical and molecular therapy: the gastrointestinal stromal tumor model. Ann Surg 2006;244: 176-184.

30 Wakai T, Kanda T, Hirota S, et al: Late resistance to imatinib therapy in a metastatic gastrointestinal stromal tumor is associated with a second KIT mutation. Br J Cancer 2004;90:2059-2061.

31 Tamborini E, Bonadiman L, Greco A, et al: A new mutation in the KIT ATP pocket causses acquired resistance to imatinib in a gastrointestinal stromal tumor patient. Gastroenterology 2004;127:294-299.

32 Heinrich MC, Corless CL, Blanke CD, Demetri GD, Joensuu H, Roberts PJ, Eisenberg BL, von Mehren M, Fletcher C, Sandau K, McDougall K, Ou W, Chen C, Fletcher JA: Molecular correlates of imatinib resistance in gastrointestinal stromal tumors. J Clin Oncol 2006;24:4764-4774.

33 Gold JS, DeMatteo RP: Neoadjuvant therapy for gastrointestinal stromal tumor (GIST): racing against resistance. Ann Surg Oncol 2007;14:1247-1248.

34 Andtbacka RHI, Ng CS, Scaife CL, Cormier JN, Hunt KK, Pisters PWT, Pollock RE, Benjamin RS, Burgess MA, Chen LL, Trent J, Patel SR, Raymond K, Feig BW: Surgical resection of gastrointestinal stromal tumors after treatment with imatinib. Ann Surg Oncol 2007; 14:14-24.

35 Aparicio T, Boige V, Sabourin JC, Crenn P, Ducreux M, LeCesne A, Bonvalot S: Prognostic factors after surgery of primary resectable gastrointestinal stromal tumours. Eur J Surg Oncol 2004;30:1098-1103.

36 Hohenberger P, Reichardt P, Gebauer B, Wardelmann E: Gastrointestinale Stromatumoren - derzeitige Konzepte der chirurgischen Therapie. Dtsch Med Wochenschr 2004;129:1817-1820.

37 Bauer S, Hartmann JT, de Wit M, et al: Resection of residual disease in patients with metastatic gastrointestinal stromal tumors responding to treatment with imatinib. Int J Cancer 2005; 117:316-332. 